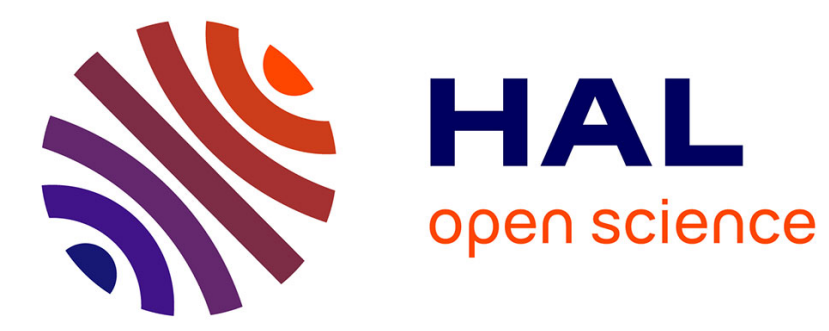

\title{
The use of a fibre optic array in a photothermal scanning microscope
}

\author{
A. Williams, C B Lim
}

\section{To cite this version:}

A. Williams, C B Lim. The use of a fibre optic array in a photothermal scanning microscope. Journal de Physique IV Proceedings, 1994, 04 (C7), pp.C7-15-C7-18. 10.1051/jp4:1994704 . jpa-00253145

\section{HAL Id: jpa-00253145 https://hal.science/jpa-00253145}

Submitted on 1 Jan 1994

HAL is a multi-disciplinary open access archive for the deposit and dissemination of scientific research documents, whether they are published or not. The documents may come from teaching and research institutions in France or abroad, or from public or private research centers.
L'archive ouverte pluridisciplinaire HAL, est destinée au dépôt et à la diffusion de documents scientifiques de niveau recherche, publiés ou non, émanant des établissements d'enseignement et de recherche français ou étrangers, des laboratoires publics ou privés. 


\title{
The use of a fibre optic array in a photothermal scanning microscope
}

\author{
A.W. Williams and C.M. $\operatorname{Lim}^{(1)}$ \\ Department of Physics, University College of Swansea, University of Wales, Swansea, U.K.
}

\begin{abstract}
A simple 7 by 7 matrix fibre optic array has been used to illuminate the surface of samples in a raster scan. By mounting the samples on a transducer the system produces an $X-Y$ photothermal scan. Samples with sub-surface features have been scanned and with the use of a graphics software package the images have reproduced the underlying thermal discontinuities in the samples.
\end{abstract}

\section{INTRODUCTION}

Photothermal scanning microscopes are used extensively to detect and characterise surface and sub-surface defects [1],[2] and [3]. Tests are usually carried out in the laboratory and the exciting beam is either moved across the sample surface or the sample is moved beneath the beam. The aim of this experiment was to determine whether a fibre optic array could be used to replace the scanning system used in conventional systems.

\section{APPARATUS AND PROCEDURE}

The fibre optic array (FOA) consists of forty-nine $1 \mathrm{~mm}$ diameter core multimode fibres. At the end of the fibre bundle which illuminates the sample the fibres are arranged in a 7 by 7 matrix. At the other end of the bundle the fibres are fixed radially, equally spaced, around the circumference of a cylindrical ring fibre holder, FH, shown in Fig.1. At the centre of this ring, a mirror, M2, driven by a stepper motor, SM, reflects. light from a laser sequentially down each fibre thus producing a raster scan at the fibre optic array. The rate of rotation of the scanning mirror was approximately $650 \mathrm{sec}$ per revolution so that each fibre was illuminated for about 15 seconds.

A schematic diagram of the apparatus is shown in Fig 2. The illumination source is a 4 watt Argon ion laser operating multimode. The light is. modulated by a mechanical chopper, $\mathrm{MC}$, at frequencies from a few Hertz to kiloHertz depending on the sample. As each fibre illuminates the sample in turn the photothermal signal produced is detected by a transducer attached to the sample. These signals then pass to a conventional lock-in system and to a PC where the data is stored prior to analysis. The output thus consists of 49 data points for both the photothermal signal and phase. In order to take account of any slight but systematic optical misalignment between the fibres and the rotating mirror the signal from each fibre was normalised to a set of photothermal signals obtained previously from a homogeneous sample. A UNIRAS $6 \mathrm{~V} 2$ graphics software package was used to give a two dimensional contour plot of the 49 data points.

(1) Now at Department of Physics, University Brunei Darussalam, Gadong 3186, Brunei 


\section{RESULTS}

A number of test samples have been scanned. The first sample we discuss was a $10 \mathrm{~mm}$ square by $0.7 \mathrm{~mm}$ thick brass plate with two parallel grooves milled out of the bottom surface. The grooves were 1.5 mm wide and $0.5 \mathrm{~mm}$ deep so that the bottom of the groove was $0.2 \mathrm{~mm}$ from the upper surface of the plate. The grooves were $2 \mathrm{~mm}$ apart. The top surface was covered with matt black paint to give maximum light absorption and the sample was mounted on to the transducer. This sample was scanned at modulation frequencies of $10.73,29.79,119.19$ and $268.18 \mathrm{~Hz}$ corresponding to thermal diffusion lengths of $1.0,0.6,0.3$ and $0.2 \mathrm{~mm}$ respectively. The raw phase data with the phase contours calculated by the UNIRAS package superimposed are shown in Fig 3. In Fig.4 the same data is shown in colour coded contours. The low frequency scans clearly show the underlying milled grooves whereas the high frequency scans in which the thermal waves barely reach the grooves do not show as cllearly the underlying features

Samples with artificial inclusions were also used for preliminary tests. Typical amongst these was a hexagonal brass nut, $5 \mathrm{~mm}$ across the flats with a $2.2 \mathrm{~mm}$ hole, embedded just below the surface of a METSET (polyester mounting plastic) sample. Again matt black paint sprayed on to the sample surface ensured maximum optical absorption. The results of the phase scans are shown in Fig 5 . The four images shown were taken at $9,14,187$ and $2100 \mathrm{~Hz}$ and correspond to thermal diffusion lengths of $0.060,0.048$, 0.013 and $0.004 \mathrm{~mm}$ respectively. At $9 \mathrm{~Hz}$ the hexagonal structure of the nut can be clearly seen. It is apparent from the $14 \mathrm{~Hz}$ image that the surface of the nut was not exactly parallel to the sample surface. This is also seen in the last two images where the thermal diffusion length approaches the depth of the upper surface of the nut. Note that the phase scale is different in each image.

For the present system the resolution of the scanned images is determined by the illuminating spot size on the sample surface which in turn depends on the fibre core diameter and the distance of the fibre optic array from the sample surface. With the array used the resolution was approximately $1.5 \mathrm{~mm}$. This could be improved with the use of smaller diameter fibres.

This study has shown that a fibre optic array can be used as a passive raster scanning system that could be used for remote scanning of samples.

\section{REFERENCES}

[1] Mandelis,A. (1987) Ed, Photoacoustic and Thermal Wave Phenomena in Semiconductors, NorthHolland, New York

[2] Hess,P., (1987) Ed. Photoacoustic, Photothermal and Photochemical Processes at Surfaces and Thin Films, Topics in Current Physics, Vol 47, Springer-Verlag, Berlin

[3] Luukala, M.V.,(1980) in Scanned Image Microscopy, Ed. Ash,A., Academic Press, London

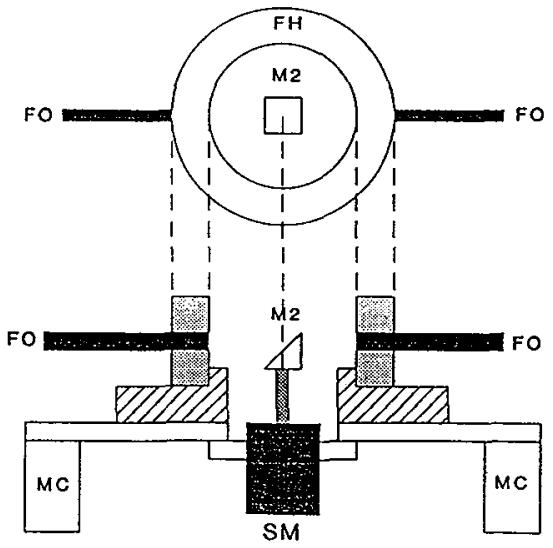

Fig. 1. 


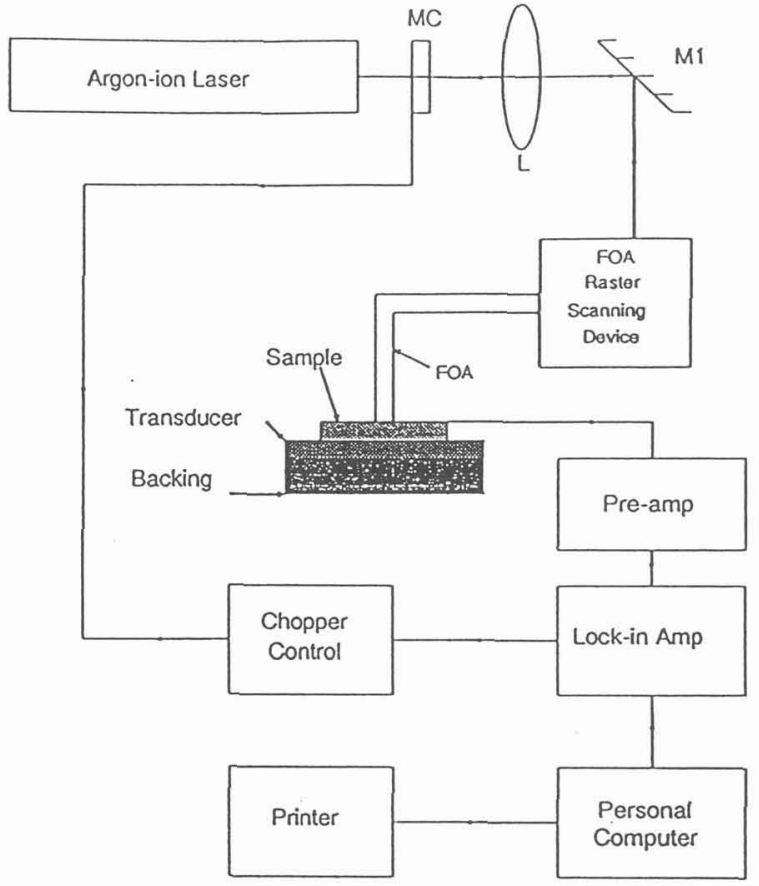

Fig. 2.
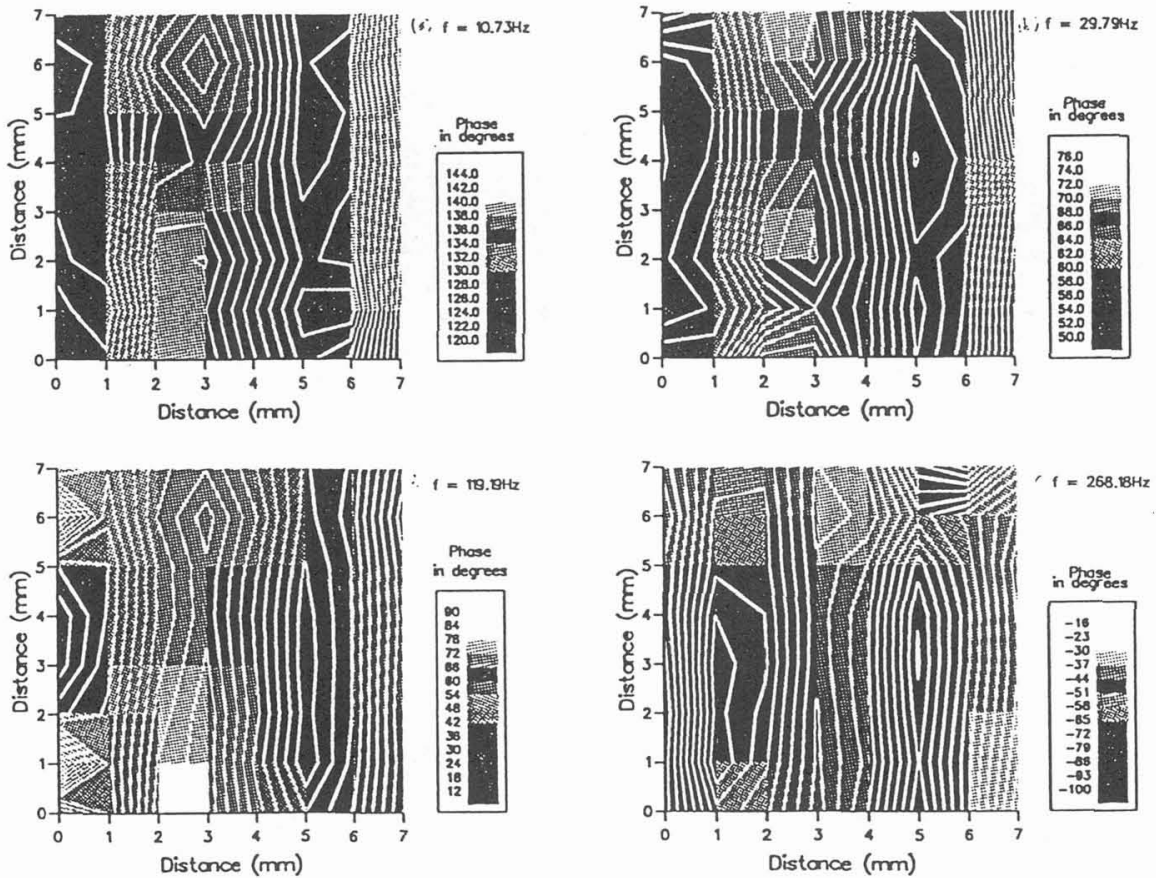

Fig. 3. 

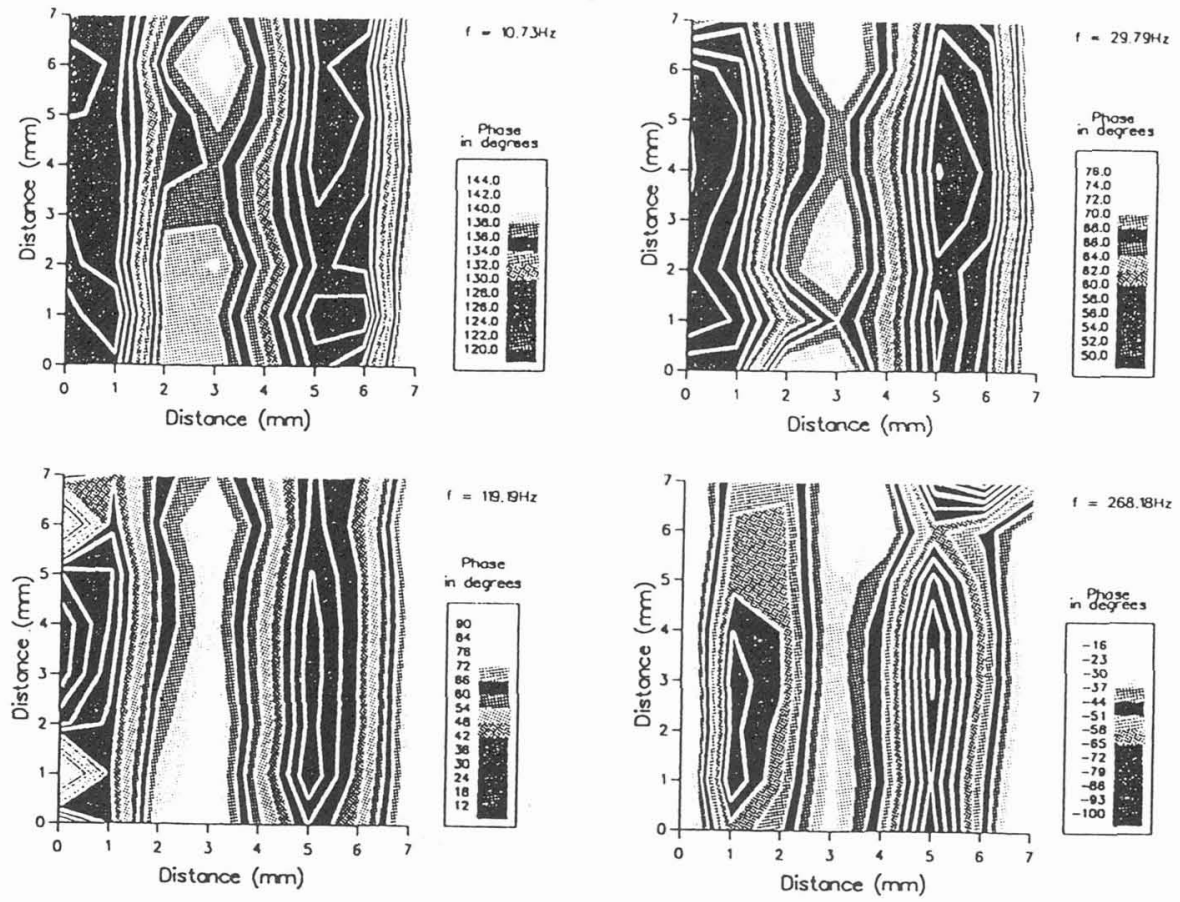

Fig. 4.
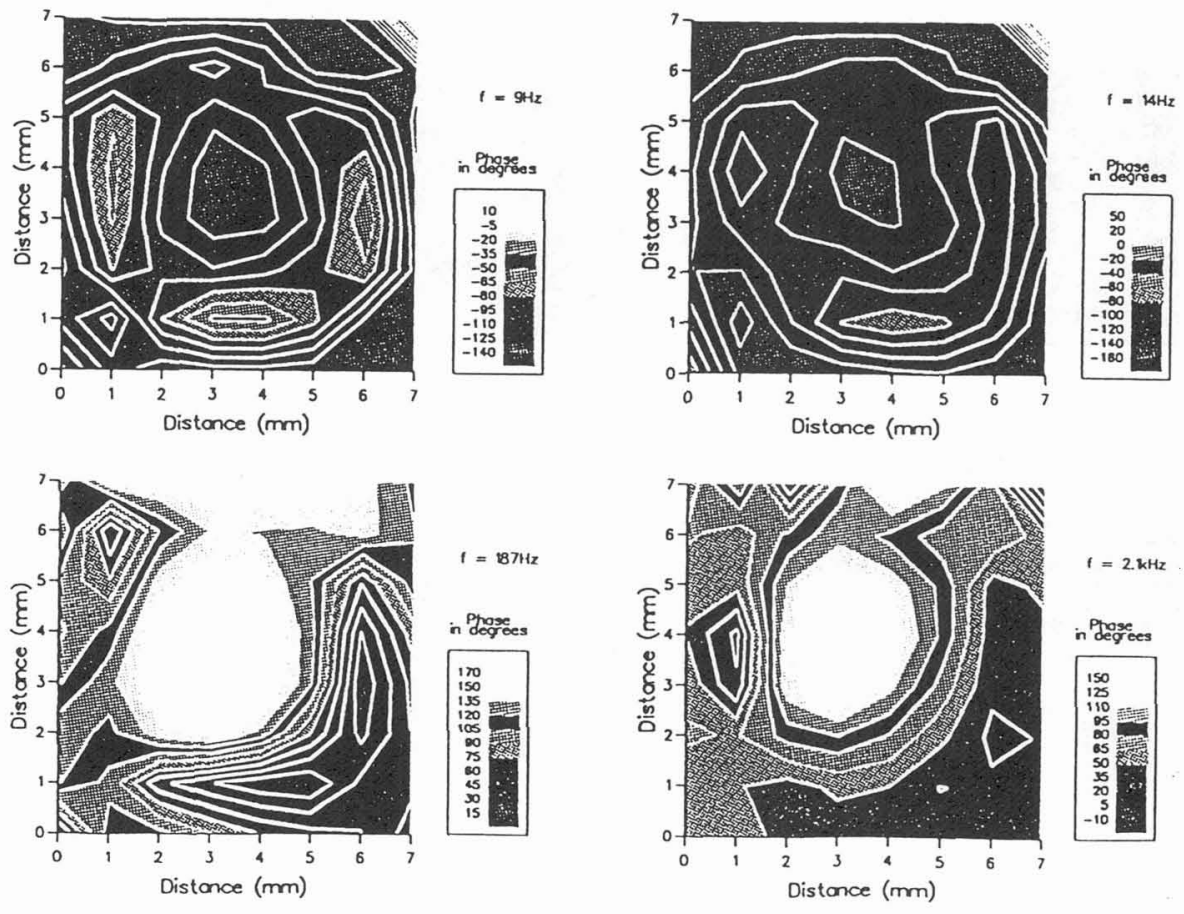

Fig. 5. 